\title{
MEDICAL ETHICS IN CLINICAL PRACTICE IN NEPAL: CHALLENGES AND WAY FORWARD
}

\author{
Shristi Raut, ${ }^{1}$ Anand Kumar ${ }^{2}$
}

\begin{abstract}
Ethics for health care professional have many components. Among them, medical ethics is one of the important but neglected component which deals with issues related to confidentiality, beneficence and non-maleficence between health care providers and stake holders. Four basic principles of medical ethics are autonomy, justice, beneficence and nonmaleficence which form the foundation of ethical clinical practice. The level of knowledge on medical ethics that medical students receive during the training is meagre and inadequate. In recent years, clinical practice has become more challenging. This is primarily due to increased opposition, aggression and violence against medical professionals at health care settings. As a result, the gap between clinicians and patients is increasing leading to diminishing trust and real/perceived allegations. In addition, the widening gap between doctors and patients has provided a space for middle men/broker to meddle, oppose and flare up the violence against treatment providers. Doctors and other medical professionals have been increasingly facing such challenges leading to circumspection in their practice, despondence, psychosocial trauma and depression. There is an urgent need of incorporation of medical ethics in undergraduate curriculum and independent hospital ethics committee consisting of experts from the hospital and outside to monitor and provide rational reasons to minimize such challenges.
\end{abstract}

KEYWORDS Medical ethics, doctor-patient relationship, hospital ethics committee, codes of conduct

1. Department of Microbiology, Universal College of Medical Sciences \& Teaching Hospital, Bhairahawa, Nepal

2. Department of Surgery, Universal College of Medical Sciences \& Teaching hospital, Bhairahawa, Nepal

DOI: https://doi.org/10.3126/jucms.v6i2.22500

\author{
For Correspondence \\ Dr. Shristi Raut \\ Department of Microbiology \\ Universal College of Medical Sciences \\ Bhairahawa, Nepal \\ Email: rautshristi@gmail.com
}




\section{INTRODUCTION}

Medical ethics is a system of principles governing medical conduct. It deals with the relationship of a physician to the patient, the patient's family, fellow physician, and society. ${ }^{1}$

Ethics of health professionals has many components, among them the following are the main ones. ${ }^{2}$

1) Biomedical

- Medical: Problems arising from relationship between patient and health professionals (confidentiality, beneficence, non-maleficence)

- Bioethics: Problems arising from scientific and technological advances (cloning, end of life problem, stem cell research, euthanasia)

2) Professional

- Deals with social relation among profession, public and government

Medical ethics is a core element of clinical practice that each and every medical professional should be aware of. Adequate knowledge and practice about medical ethics strengthens the quality of health service delivery to the community.

\section{History of medical ethics in Nepal}

Therapeutic medicine has been practiced in Nepal since ancient time. Although historical accounts are difficult to report, code of conducts seem to be existing since ancient time in Nepal. One of which that has been well documented is the Charaka Samhita. Together with the introduction of modern medicine in Nepal, the Hippocratic Oath has been the core element of ethical practice.

\section{Foundation of medical ethics}

Foundation of medical ethics is based on four principles and is mandatory for medical professionals.

1) Principle of autonomy: Mentally sound patient has a right to make decision regarding his treatment.

2) Principle of beneficence: Any intervention offered to the patient has to be beneficial otherwise that should not be performed.

3) Principle of non-maleficence: If there are possible ways to minimize harmful side effects, these have to be discussed with the patients.

4) Principle of justice: Limited health resources have to be fairly and equitably distributed among people without any biasness based on patient's characteristics for example age, gender, ethnicity, race, social status and religion.

These four basic principles of medical ethics form the foundation for health professionals to direct and maintain ethical clinical practices in all circumstances. ${ }^{4-6}$

\section{Clinical practice challenges and way forward}

The methodology of clinical practice has changed significantly from Hippocratic tradition before $400 \mathrm{BC}$ to $21^{\text {st }}$ century medicine. One of the most referred ethical principles, the Hippocratic Oath mainly focus on "Primum non nocere" i.e. 'doing good to the patient without harm'. However, together with the recent developments in medical practice, ethicists and medical practitioners have realized that it needs revision to address some of the pertinent issues like worsening security at workplace for medical practitioners.

In recent years, the violence against the health workers has been increasing and has left health workforce to become circumspect. ${ }^{7}$ Such a scenario can lead doctors and health workers in a permanent despondence leading to negative impacts on services they provide. For example, inability to work in fearless environment can lead to incertitude leading to excessive referrals. Such referrals could be accentuated by improper and aggressive communication by the patient or their relative at the work place. Such a fear also can lead to a lack of compassion. Lack of compassion and intimacy in doctor-patient relationship can ultimately deliberate insouciant attitudes towards patients. ${ }^{2}$ Such a scenario is unfortunate in doctor-patients' relationship and lead to compromised quality of care. Also, can create a vulnerable situation where health care itself will be considered as a "business enterprise". The value of intimacy, relationship and care cannot be equated alone on professional grounds. It has a broader relevance when it comes to health care that often blends with formal care to informal communication and professional management to intimate care.

In Nepal, medical fraternity practices traditional system of paternalistic care. This for example, can mean that patients either are not capable of understanding the technicality of care provided or simply do not get an opportunity to decide. While this is globally prevalent, simplification of modalities of treatment and the medical jargons are of paramount importance for patients to practice the voluntariness in their decision making. Complete understanding of the modalities of the treatment including the options available for treatment are vital for patients to make a valid choice. The range of this freedom for patients are often overlooked in developing countries. Deprived autonomy for patients over the period in regards to how they could make decisions can also accentuate 
an existing hegemony from the medical workforce. The later can have further repercussions such as opposition, resentment and sometimes petty agitation rooted to patients' past experience.

Lack of knowledge and skills in clinical practitioners can result into dreadful consequences. Bearing a good intentioned care cannot obviate the need for a sound knowledge of the discipline. Whilst it is true that the level of knowledge and expertise varies amongst the health care professionals yet patient may deserve the sound care unconditionally. In this regard, it is treating health workers' responsibility to provide comprehensive message and refer to the best possible expert in the field. Such a practice, however, has several challenges that primarily hinges on the motives at individual and institutional level. It is also critical to ensure patients to understand the treatment dynamics. The variables of treatment dynamics depend upon how each individual respond to the treatment based on its pharmacodynamics and pharmacogenomics.

The recent trend of increasing commercialization of health care and inability to conceive that the medical care is not a guaranteed approach has given rise to loss of trust and confidence. These issues also need to be revisited in order to maintain the standard of health care in the country.

\section{Medical etiquette (The hospital)}

Health care and clinical practice is not as straight science as mathematics and entails a blend of arts and science. Therefore, anticipation of medical science to cure for all disease and guaranteed approach is a fundamental fallacy. It is essential that all health care providers be cognizant of this particular issue rather than being prescriptive and definitive on their treatment. The inadvertent consequences can be a fate of any treatment. A recommended approach would be to advise patient on the lack of certitude and the inherent unpredictability in the treatment offered.

While the limitations of treatment and health care is essential to understand, it is also clear that treatment options in Nepal and the health care providers often tend to hype up the way they provide the treatment. That for example includes unnecessary and supercilious advertisement on self, health care and hospitals. Sometimes, these advertisements and claims of guaranteed treatment can become problematic when the outcome of the treatment may not succeed. Also, any failure on promised outcome from the health care providers can jeopardize the prestige and the trust of entire medical fraternity. Implementation of the current law by punishing health care professional if any harm is made to the patients due to medical negligence might also be an impediment on the treatment. Policy makers need to be aware of such an approach and promptly need to take an appropriate action. Recent trends including the policy updates further warrants the need of medical ethics course in all institutions at all levels.

Moreover, substandard practice by some health care institutions is a common issue faced by medicos in Nepal. This can stigmatize the entire health care providers. Poor governance and impunity for such approach act are the impediments for complete implementation of medical ethics and consumer protection act for health care. ${ }^{8}$

\section{Teaching and evaluation of medical ethics to under- graduate students}

Given the backdrop of the recent developments and untoward trends in Nepalese health care practice, there is an urgent need for reformation in Nepal's medical education. ${ }^{9}$ There is a clear need for a greater engagement of medical students to ethics through integrating the courses in the curriculum. The limited teaching on medical ethics under the discipline of Forensic Medicine is inadequate to keep up with the current trend and development, particularly, to comprehend and tackle the disputes and misunderstandings between clinical practitioners and patients. Rather teaching ethics should be incorporated in all the fields of medical sciences. Moreover, Hippocratic Oath is the most popular and one of the revered codes of conduct in medical ethics, it has been redefined in major documents like Nuremberg code and Helsinki declaration of which significant number of clinicians even in a tertiary care hospital Tribhuvan University Teaching Hospital of Nepal were unaware of. ${ }^{10}$

Study on assessment of educational needs of medical ethics reveals 'doctor-patient relationship' and 'professionalism' are the two major issues for undergraduate medical curriculum. ${ }^{11}$ Since clinical practice is becoming more challenging in recent years, medical ethics has to be taught as a major subject and it needs to be evaluated properly. Even though, medical ethics has been greatly emphasized by doctors in medical colleges, the paucity of trained resource persons in this field has been paradoxical leading to lack of implementation. In addition, as this subject has not been specified to any particular department, responsibility allocations are compromised and thus affects the teaching for undergraduate medical students. ${ }^{12}$ There is also lack of standard teaching-learning methods and evaluation tools for medical ethics. Traditional lecture method has to be replaced by more interactive and participatory approaches. ${ }^{13}$ Problem-based learning and small group discussion are two methods which are better than traditional lecture and is strongly recommended for ethics education. ${ }^{14}$

\section{Hospital Ethics Committee}

Healthcare ethics committee (HEC) has been existing in United States since early 1980s. Research ethics committees 
are well established in United Kingdom. ${ }^{15}$ Clinical ethics committee which deals with ethical issues arising out of clinical practice and research is ever growing. Clinicians are frequently facing ethical problems during their work irrespective of their years of experience and knowledge. In addition to increasing workload in hospital settings for clinicians, legal and ethical issues related to patient care may further add a layer of burden and exhaustion. HEC is already in a great need for reformation in organizational infrastructure and administrative management to tackle ethical consultation of such issues. Another challenge has been a need for human resources experienced enough in medico-legal ethics including its application in medical practice.

A hospital based human infrastructure as in charge of ethical issues are obviously seen as supporting health care providers working in the hospital. Given the strain in human resources (literacy in medical ethics and medical practice), it may also be difficult to form an external ethics committee independent of hospital. In addition, a legal practitioner may not be fully cognizant of medical details related to the issues, which even though may be appropriate in the legal lenses. Amidst these clear challenges, there is a need for increasing the literacy on medical ethics amongst young medical students including a mandatory course on ethical medical practice. Contemporarily, a committee consisting of expert on medical ethics, medical practitioners and litigation from both the hospital and outside is essential to govern and guard the ethics of medical practice including the security in health care settings.

\section{CONCLUSION}

The widespread challenges of ethical issues are realized by all health care professionals, nonetheless, medical ethics has not received adequate attention in regards to its implementation. Medical ethics has to be incorporated in undergraduate medical curriculum and assessed theoretically and practically similar to other subjects. In addition, it is mandatory to establish a hospital ethics committee composed of experts in pertinent fields (medical ethics, practice and litigation), both from the hospital and outside hospital to deal with ethical issues encountered by health professionals during patient care.

\section{ACKNOWLEDGEMENTS}

We would like to express our sincere gratitude to Dr. Bipin Adhikari from Mahidol-Oxford Tropical Medicine Research Unit for his suggestions and reviews.

\section{CONFLICT OF INTERESTS}

Both authors of this manuscript declare that there is no conflict of interests.

\section{AUTHORS' CONTRIBUTIONS}

AK provided initial concept and intellectual opinion, SR prepared the manuscript.

\section{REFERENCES}

1. Taber CW. Taber's cyclopedic medical dictionary. $20^{\text {th }}$ edn: p746.Pub: F.A. Davis Company. 2001

2. Kumar A. Reinventing the society. Ethics and values in medicine, p 122-133. Pub: Macmillan India Ltd. 2013.

3. Jayweera BA: Ethical issues in health, Discussion paper presented at SEA Advisory Committee on Health Research, Dharan, Nepal, April'96.

4. Code of ethics and Professional conducts. Nepal medical council 2017.p-3.

5. Summers J, Morrison E. Principles of healthcare ethics. $2^{\text {nd }}$ ed. Sudbury: Jones and Bartlett Publishers;2009. p.41-58.

6. Beauchamp TL, Childress JF. Principles of bioethics. USA: Oxford University Press; 2001.

7. Magar A. Violence against doctors in Nepal. J Nepal Med Assoc. 2013;52(192): I-II.

8. Adhikari B. Organ and human trafficking in Nepal. Lancet.2016;387(10031):1907.

9. Adhikari B, Mishra SR. Urgent need for reform in Nepal's medical education. Lancet. 2016; 388:2739.

10. Adhikari S, Paudel K, Aro AR, Adhikari TB, Adhikari B, Mishra SR. Knowledge, attitude and practice of healthcare ethics among resident doctors and ward nurses from a resource poor setting, Nepal. BMC Med Ethics.2016;17-68.

11. Asghari F, Samadi A, Rashidian A. Medical ethics course for undergraduate medical students: a needs assessment study. J Med Ethics Hist Med, 2013, 6:7.

12. Adhikari R. Ethics in Undergraduate Medical Courses in Nepal. Kathmandu Univ Med J. 2014;11(1):1-3.

13. Alkabba AF, Hussein GM, Kasule OH, Jarallah J, Alrukhan M, AlrashidA.Teaching and evaluation methods of medical ethics in the Saudi public medical colleges:cross-sectional questionnaire study. BMC Medical Education 2013, 13:122.

14. Haidari A, Adeli SH, Taziki SA, Akbari V, Ghadir MR, MoosaviMovahhed SM et al. Teaching medical ethics:problem-based learning or small group discussion? J Med Ethics Hist Med, 2013, 6:1.

15. Slowther AM. Clinical ethics committee. BMJ2000;321:649-50. 